REVENUE NEUTRAL TRADE REFORM

WITH MANY HOUSEHOLDS, QUOTAS AND TARIFFS

James E. Anderson

Working Paper 6181 


\title{
REVENUE NEUTRAL TRADE REFORM WITH MANY HOUSEHOLDS, QUOTAS AND TARIFFS
}

\author{
James E. Anderson
}

Working Paper 6181

http://www.nber.org/papers/w6181

\section{NATIONAL BUREAU OF ECONOMIC RESEARCH 1050 Massachusetts Avenue \\ Cambridge, MA 02138 \\ September 1997}

I am grateful to Dani Rodrik for helpful comments. This paper is part of NBER's research program in International Trade and Investment. Any opinions expressed are those of the author and not those of the National Bureau of Economic Research.

(C) 1997 by James E. Anderson. All rights reserved. Short sections of text, not to exceed two paragraphs, may be quoted without explicit permission provided that full credit, including $\mathbb{C}$ notice, is given to the source. 
Revenue Neutral Trade Reform with Many

Households, Quotas and Tariffs

James E. Anderson

NBER Working Paper No. 6181

September 1997

JEL Nos. F13, H21

International Trade and Investment

\begin{abstract}
Government budget balance forces the endogenous use of distortionary tax instruments when an exogenous reform is implemented. The aggregate efficiency of such reforms is based on comparisons of simple summary measures of the Marginal Cost of Funds of the various tariff or quota changes with the Marginal Cost of Funds of the alternative taxes, or of the Marginal Benefit of Government supplied goods. The aggregate efficiency of tariff liberalization is dubious, while quota liberalization is more likely to be efficient. Social welfare rises with aggregate efficiency unless distribution effects are perverse. Plausible sufficient conditions for non-perverse distributional effects are provided. The results frame a diagnostic method for sensitivity analysis in evaluations of trade and tax policies.
\end{abstract}

James E. Anderson

Department of Economics

Boston College

Chestnut Hill, MA 02167

and NBER

james.anderson@bc.edu 


\section{Table of Contents}

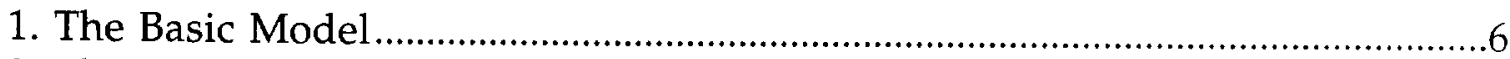

2. The Marginal Cost of Funds Concept.............................................................11

3. The MCF of Quotas, Tariffs and Rent-retaining Tariffs ..................................14

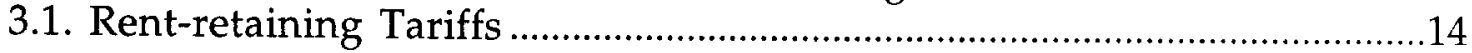

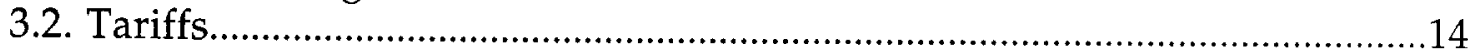

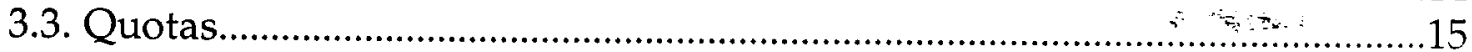

4. Reform Propositions ...................................................................................18

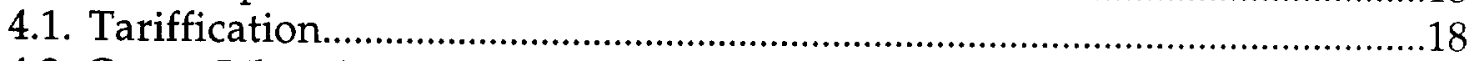

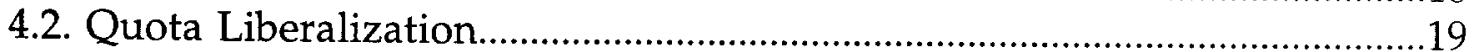

5. When is Efficiency Enough?: The Many Household Case ................................21

5.1. The Many Household Setup …………………….....................................22

5.2. Tariff Reform in the Many Household Case .............................................24

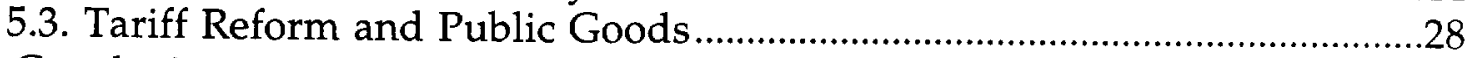

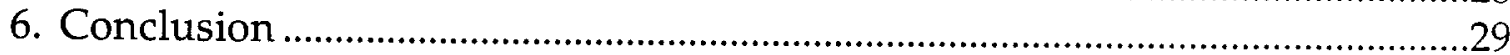

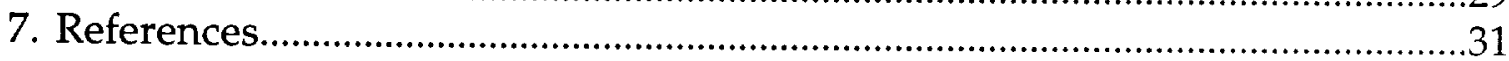

8. Appendix. Government Expenditure Cuts..........................................................33 
Trade reform is typically analyzed assuming that the government offsets revenue losses with lump sum transfers behind the scenes. The unrealism of this assumption is especially troublesome when the ability of the government to borrow is restricted, either by credit markets as it is for many developing nations or by political agreements as it now is for-most developed nations. This paper considers trade reform when revenue cuts must be offset with increases in other forms of distortionary taxation or with government spending cuts.

The desirability of trade reform in this setting turns out to be an empirical question which cannot be decided from a priori economic theory. To answer this question it is essential to have the appropriate theoretical tools with which to approach and handle the complexity of the modern Computable General Equilibrium (CGE) models in which the empirical work must be carried on. The welfare analysis of trade reform with lump sum redistribution (see for example Anderson and Neary, 1992) is not adequate. The public economics literature develops and uses the Marginal welfare Cost of Funds (MCF) concept to analyze tradeoffs among distortionary instruments by comparing the MCFs of the competing instruments (see especially Ahmad and Stern, 1990). Anderson (1997) redefines the MCF in a dual model as a compensated (real income constant) concept. The compensated MCF is essential for dealing with the practical question of the desirability of tariff reform, because it permits comparison of results across rival CGE models in an intuitive decomposition. This paper refines and generalizes the MCF concept to include the MCF of any government instrument, including quotas and the rent retaining tariffs which are commonly found with quotas. Also, the tariff MCF is reexamined in the presence of quotas. Finally, the analysis focuses on the question of when it is legitimate for empirical methods to neglect equity. Sufficient conditions are developed under which comparison of (aggregate) MCFs is all that is needed, despite substantial ignorance about the distributional effects of trade policy and especially about ethical weights. 
As a means of providing focus for the concept of the MCF of various instruments, gradual reform propositions are offered. Trade reform is efficient in the realistic case of the active government budget constraint if the Marginal Cost of Funds (MCF) of the exogenously changed trade instrument exceeds the MCF of the endogenous instrument which replaces the-lost revenue. Diamond and Mirrlees (1971) show that optimal consumption taxation dominates taxation which discriminates between suppliers of homogeneous goods, as trade taxes do. For this reason, trade taxation is inefficient. ${ }^{1}$ Despite this, Anderson (1997) shows that the MCF of consumption taxation cannot generally be ranked relative to the MCF of trade taxation. (Anderson provides very strong sufficient conditions for a gradual Diamond-Mirrlees proposition.)

This paper takes up the desirability of quota liberalization and shows that more definite theoretical rankings are possible than with tariff liberalization. To economize on notation, consumption taxation is disallowed, so that the endogenous alternative tax change is a tariff change (on goods not subject to quota). This procedure is justified by noting that the MCFs of both consumption taxes and tariffs may be taken to exceed one under the same qualifications (entered below), hence the endogenous tariff stands in for the consumption or income tax with MCF greater than one. Two reforms are analyzed. First, tariffication replaces quotas with tariffs such that the quota is nonbinding. The MCF of rent-retaining tariffs is less than or equal to one --they may dominate lump sum taxes if they take back some rent lost to foreigners. The revenue raised by the increase in the rent-retaining tariff is used here to reduce other tariffs endogenously, which under a substitutability restriction have MCF greater than one, so tariffication is indeed welfareimproving. Second, quota increases are analyzed, with three subcases. Liberalization of pure Voluntary Export Restraints (VERs), which give away

\footnotetext{
${ }^{1}$ For non-homogeneous goods, there is no general reason to expect the optimal tax on the import to be less than or equal to that on its domestic counterpart. Optimal taxation may require what
} 
all rent, is efficient under a substitution effect restriction. If substitution between public goods and quotas and between tariff-ridden goods and quotas is weak, the MCF of VERs is negative --- a rise in quotas both raises revenue (from rent-retaining tariffs) and lowers the cost of maintaining the private agent's utility. The endogenous tariff must also be lowered to maintain budget balance, and on both counts welfare improves. In contrast, with strong cross effects, under plausible conditions the MCF of VERs is positive but less than one. In this case, liberalization of quotas is welfare decreasing if the MCF of the endogenous tax is greater than one. The last subcase is pure auction quotas, which retain all rent, and are equivalent to tariffs; hence revert to the cases analyzed in Anderson (1997) with no or only slight presumption obtaining for liberalization. International rent sharing is thus critically important (see also Anderson and Neary, 1992), but in addition the sharing of rent between private agents and the government plays a role. ${ }^{2}$

In contrast to these guarded and qualified results, the classic trade reform analysis uses a 'passive' government budget constraint with lump sum transfers to replace the lost revenue. The revenue-replacing lump sum taxes have MCF equal to one. The efficiency comparison of MCFs reduces to MCF-1, or the marginal dead weight loss (marginal excess burden) of the tariff change. Uniform radial tariff cuts are always desirable because they obtain a generalized Harberger triangle (Hatta, 1977). Since marginal dead weight loss and MCF have no necessary close relationship, the conclusions from the classic literature cannot be applied to the distortionary tax case.

will be interpreted as trade taxation by the World Trade Organization, hence trade agreements may inefficiently restrict revenue taxation.

${ }^{2}$ For developed countries, nontariff barriers are the main form of protection, and the disposition of the rent so generated is a central part of the policy analysis. For VERs, the rent shifted to foreigners is understood as a bribe for accepting some loss of market share, while at the same time the countries requesting the VER use substantial tariffs to capture a share of the rent. For domestic quotas, Bergsten et al (1987) propose helping the US government budget deficit with auction of quota rights and point to recent experience in Australia and New Zealand with quota license auctions. As for developing nations, the standard World Bank reform recommendation has for more than a decade been to convert quotas to tariffs ('tariffication') and then to move toward uniform tariffs, all the while respecting the need to preserve government revenue from the distortion of trade. 
The Marginal Cost of Funds is developed here in a dual model with three advantages. First, it reveals the connection of the family of MCFs of the various instruments in a clean way. Second, since the MCF is defined here as a compensated concept, which is necessary for extension to the many household case. Third, compensation measures such as the compensated MCF can be compared across different representations of the same economy or even from different economies, drawing from a range of Computable General Equilibrium (CGE) models. In practice this comparability is extremely useful, since there is no agreement on which CGE model is the right one.

Efficiency of trade reform need not imply equity. The classic analysis is able to assume that any efficiency gains are shared out equitably via lump sum redistribution taking place (implicitly) backstage. With distortionary instruments only, the separation of efficiency and equity considerations embedded in the representative agent assumption can only be rationalized by a hunch that equity considerations may not matter in many practical cases. This hunch is explicitly formulated here with sufficient conditions for an efficient reform to imply a rise in social welfare.

The approach of this paper to dealing with equity concerns occupies a middle ground between two poles in the earlier literature. Diewert, TurunenRed and Woodland (1989) show that there exist commodity tax changes such that a uniform radial cut in trade taxes combined with an unspecified commodity tax change can be guaranteed to raise every household's welfare. The opposite pole in specificity is found in the optimal tax literature (see for example Atkinson and Stiglitz, 1980) which characterizes the many household optimal tax structure when commodity taxation only is available. The formulae require knowing the full details of both the general equilibrium income linkages and the welfare weights. In between these poles, the present approach gives simple concrete rules for the tax reform assuming condition on 'nonperverse equity effects' holds. Under the sufficient condition, a uniform radial cut in trade taxes combined with a uniform radial increase in consumption taxes is welfare improving if the MCF of trade taxes 
exceeds that of consumption taxes. The magnitude of the MCFs cannot be pinned down from theory alone, but is in practice at least arguably known from simulations of CGE models. ${ }^{3}$

The middle ground of this paper is attractive because the Paretoimproving approach cannot recommend a specific tax reform from theory while the full information approach requires information which is generally not available. The analyst's greatest ignorance is about distributional relations, both with respect to general equilibrium linkages of goods and factor prices ${ }^{4}$ and with respect to the appropriate ethical weights. The representative agent model avoids having to specify such details, and is adequate when the sufficient conditions are plausible in the context of the policy to be analyzed. ${ }^{5}$

The results of this paper frame a diagnostic method for two types of sensitivity analysis in evaluations of trade and tax policies. First, the sufficient conditions point to a procedure for the simulation of plausible models of heterogeneous agents and sets of reasonable ethical weights to see how widely relevant the conditions may be. Second, given the representative agent approach, several CGE models are typically plausible in the face of ignorance about detailed economic structure. ${ }^{6}$ In comparing policy analyses based on several plausible models, MCFs provide a useful basis. They are index

\footnotetext{
${ }^{3}$ In further contrast, the classic approach with lump sum transfers allows specific recommendations from theory alone. A uniform radial reduction in tariffs always reduces marginal dead weight loss (and hence welfare under a stability condition) if the only distortions are tariffs (Hatta, 1977). Uniform radial reductions of tariffs in the presence of quotas is welfare improving under substitutability restrictions (Anderson and Neary, 1992). Quota liberalization with tariffs is likewise welfare improving under substitutability restrictions.

${ }^{4}$ The recent great interest in the role of rising international trade in explaining the rising differential between skilled and unskilled wages illustrates this ignorance very well. In principle, the issue is easily resolved with a CGE model: just feed in a set of changes in technology, factor supply and international prices and decompose the effects on the set of factor prices. The difficulty is that there is no agreement on which CGE model to use and the results will be very sensitive to specification of the production sector. Therefore the trade economists who have contributed to this literature have not even attempted a CGE approach.

${ }^{5}$ In contrast, Levy and van Wijnbergen (1995) is a notable example of a Pareto-improving simulation approach to the obvious ethical problem posed by Mexico's accession to NAFTA. ${ }^{6}$ The recent spate of analyses of NAFTA and of the European single market are an example.
} 
numbers which summarize in an intuitive way the properties of complex tax systems and substitution effects systems interacting in general equilibrium. Sensitivity analysis with MCFs provides insight into both the assumptions about substitution effects and the aggregation assumptions in consumption, production, trade and taxes. It may be that measures of the MCF of tariffs and of other instruments can be placed in reasonable ranges which are not too sensitive to model structure, substitution parameters or aggregation. Anderson (1997) provides an empirical example of welfare-decreasing trade liberalization for Korea in 1963 despite high initial tariffs. This suggests a high payoff to more research on MCFs of tariffs and consumption taxes, as well as the other instruments analyzed in this paper.

Section 1 presents the formal basic model. Section 2 analyzes the MCF concept. Section 3 presents the results on tariff reform with quotas and in the presence of an active government budget constraint. Section 4 takes up quota reform. Section 5 extends the analysis to the many household case. Section 6 concludes.

\section{The Basic Model}

The model throughout is of a competitive economy with no distortions other than fiscal distortions. All tradable goods face fixed international prices. The public good is assumed to be nontradable, so endogenous changes in its cost affect the MCFs of various taxes. Other nontradable goods in practice form an important part of the tax base alternative to trade taxes, but are ruled out here for simplicity (see Anderson, 1997 for the complications of taxable nontraded goods). Substitutability restrictions will be introduced as needed. Finally, the model is static. This simplifying assumption is most appropriate for a credit constrained government and economy and can also be rationalized when political agreements constrain the government budget deficit.

The basic building blocks are the private and public sector budget constraints. These are built up from the expenditure and gross domestic 
product functions, with some intermediate construction involving the quantity restricted forms of these functions.

The consumer's expenditure function $e(\pi, p, r, u)$ gives the minimum value of expenditure on private goods at prices $\pi$ and $p$ and public goods at marginal valuation $r$ required to support utility level $u$. The gross domestic product function $g\left(\pi, \mathrm{p}, \mathrm{r}^{*}, \mathrm{v}\right)$ gives the maximum value of production of private goods at price $\pi$ and $\mathrm{p}$ and public goods at marginal resource cost $\mathrm{r}^{*}$ using the vector of primary inputs $\mathrm{v}$ in a convex technology. The value $g$ also measures the total payments to factors. (If necessary, a diminishing returns technology can be augmented by dummy factors to receive the residual returns.) There are also some untaxed tradable goods with unit price which are suppressed as active arguments, so that $\pi$ and $p$ are relative price vectors. Variable labels appearing as subscripts denote partial differentiation.

The level of public good production $G$ and the level of the quota vector $q$ are both set exogenously by the government, and it is convenient to work with quantity restricted functions which include $G$ and $q$ as an argument. First, define the private goods expenditure and private goods GDP functions as:

$$
\begin{aligned}
& \bar{e}(\pi, p, G, u)=\max _{r}\{\mathrm{e}(\pi, \mathrm{p}, \mathrm{r}, \mathrm{u})-r \mathrm{G}\} \\
& \tilde{g}(\pi, p, G, v)=\min _{r^{*}}\left\{\mathrm{~g}\left(\pi, \mathrm{p}, r^{*}, \mathrm{v}\right)-r^{*} \mathrm{G}\right\} .
\end{aligned}
$$

See Anderson and Neary (1992) for a similar development and further details. Then the distorted net expenditure on private unconstrained goods at domestic prices is defined as

$$
E(\pi, q, G, u, v)=\max _{p}\left\{\bar{e}(\pi, p, G, u)-\tilde{g}(\pi, p, G, v)-p^{\prime} q\right\} .
$$

The distorted net expenditure function has several important properties needed below. First

$$
-E_{G}=r-r^{*}
$$

the gap between the virtual price of the public goods $r$ (equal to $-\bar{e}_{G}$ ) and the marginal cost $r^{*}$ (equal to $-\tilde{g}_{G}$ ). Second, $E_{\pi}$ is the vector of excess demands. 
Third, $-E_{q}$ is equal to $p$, the virtual (and domestic) price of the quota constrained good.

A critical issue in the analysis of quotas is the disposition of the rent. Based on the data available (Anderson, 1991, Erzan, Krishna and Tan, 1994), quota rent is typically split between foreign and domestic private agents and the government of at least one of the countries. Thus the approach here encompasses all three special cases in which domestic private agents, domestic government or foreign agents alone get the rent. ${ }^{7}$ The total rent per unit is equal to the gap between the foreign supply price and the domestic demand price. The domestic price of quota constrained goods is equal to $-E_{\eta}$ and the international price is equal to $p^{*}$. The government retains some rent by means of a rent-retaining tariff vector $t^{q}$. In this, it has a first mover advantage. The balance of the rent $-E_{q}-p^{*}-t^{q}$ is split between foreign and domestic agents, with $\omega$ per cent going to foreign agents. (The fraction $\omega$ can alternatively be viewed as lost to rent seeking, where rent seeking simply uses up foreign exchange.) The domestic portion of 1- $\omega$ percent is split between the government and the private agents, with $\alpha$ per cent going to the government. The government gets all the rent with $t^{q}$ equal to zero, $\omega$ equal to zero and $\alpha$ equal to one --- the perfect rent extracting auction case. Foreign agents get all the rent with $t^{q}$ equal to zero, $\omega$ equal to one and $\alpha$ equal to zero, the pure VER case. Finally, the domestic private agent gets all the rent with $t^{q}$ equal to zero, $\omega$ equal to zero and $\alpha$ equal to zero, the import quota with licenses given away by the government.

The tax instruments of the government include rent-retaining tariffs $t^{q}$, implicit methods to retain the fraction $\alpha$ of domestic rent, and ordinary tariffs $\pi-\pi^{*}$ (and $\mathrm{p}-\mathrm{p}^{*}$ when it is convenient to have two classes of goods

\footnotetext{
${ }^{7}$ The rent shares are to be understood as reflecting some underlying bargaining game between license buyers and the government on the one hand and between license holders and the foreign sellers of some oligopolistically supplied product on the other hand. The shares are assumed to be constant for simplicity. In general there is no good reason to expect the shares $\alpha$ and $\omega$ to be constant with respect to changes in the quota or other government instruments, but an
} 
subject to tariff). It is convenient to introduce as an incipient possibility the lump sum transfer $\rho$ from the government to the private agent. All untaxed goods have prices equal to unity and are not explicitly treated.

The next step is to build the private and government budget constraints. The private sector enjoys income from factor payments in both private and public production as well as whatever quota rent is retained. The income is spent on both unconstrained and quota constrained goods. The private budget constraint is:

$$
\begin{aligned}
\Pi\left(\pi, q, G, t^{q}, \rho, u, v\right) & \equiv E(\pi, q, G, u, v)-E_{q}{ }^{\prime} q+G \bar{g}_{G}(\pi, q, G, u, v) \\
& -(1-\omega)(1-\alpha)\left[-E_{q}-p^{*}-t^{q}\right]^{\prime} q-\rho \\
& =0 .
\end{aligned}
$$

The second term adds to the net private expenditure on unconstrained goods the domestic value of the quota consumption. The third (negative) term deducts from private net expenditure the factor payments received from public production, where $\bar{g}(\pi, q, G, u, v) \equiv \widetilde{g}[\pi, p(\pi, q, G, u, v), G, v]$ and $p(\cdot)=-E_{q}$. The fourth term deducts from net expenditure the quota rent retained by the private sector. The last term is the lump sum transfer from the government (or to the government if negative).

The government budget constraint expresses the requirement that tax receipts cover government expenditures. Formally, the constraint is:

$$
\begin{aligned}
\Gamma\left(\pi, q, G, t^{q}, \rho, u, v\right) & \equiv\left(\pi-\pi^{*}\right)^{\prime} E_{\pi}(\pi, q, G, u, v)+t^{q}{ }^{\prime} q+\alpha(1-\omega)\left[-E_{u}-p^{*}-t^{q}\right]^{\prime} q \\
& +G \bar{g}_{G}(\pi, q, G, u, v)-\rho \\
& =\beta .
\end{aligned}
$$

The first two terms of $\Gamma$ are the tariff revenue, while the third term is the quota rent secured by the government (other than that obtained with the rent-retaining tariffs). The fourth term is equal to minus the government expenditure on the public good while the last term is equal to minus the transfer to the private sector. The net government budget surplus is $\beta$, introduced as an incipient possibility for expositional convenience. 
The standard analysis imposes lump sum taxation $\rho$ as the endogenous means of balancing the government budget. Solving (1.6) for $\rho$ and substituting into (1.5), the social budget constraint is (with $\beta$ equal to zero):

$$
\begin{aligned}
B\left(\pi, q, G, t^{q}, u, v\right) & \equiv E(\pi, q, G, u, v)-E_{q}^{\prime} q \\
& -\left(\pi-\pi^{*}\right)^{\prime} E_{\pi}-t^{q^{\prime}} q-(1-\omega)\left[-E_{q}-p^{*}-t^{q}\right] \\
& =0 .
\end{aligned}
$$

Here $B(\cdot)$ is defined as the balance of trade function. Anderson and Neary (1992) use this model in a slightly simpler version to analyze trade reform.

Three aspects of government/private sector interaction are suppressed with the assumption of endogenous lump sum redistribution. First, the endogenous lump sum tax becomes implicit. Second, the rent shares of the government and private agents are consolidated, so that the parameter $\alpha$ is irrelevant. Third, the share of domestic product accounted for by the public good is irrelevant (directly, although indirectly the level of $G$ of course affects the level of equilibrium $u$ ).

The method of this paper is to perturb the two equation system (1.5)(1.6) with respect to an exogenous instrument understanding that some other fiscal instrument must be altered endogenously to ensure that the government budget constraint is met at the new equilibrium level of utility. To reduce the dimensionality of the problem, all instrument changes are set up as scalar changes. Tariff changes are uniform radial changes, proportional to the original tariff vector at scalar rate $\mathrm{d} \tau$. Quota changes are proportional to the original quota vector. Let the exogenous scalar change in the instrument to be reformed be $\mathrm{d} \theta$. The general method is to first solve the government budget constraint for $\mathrm{d} \tau / \mathrm{d} \theta$, then substitute into the differential of the private budget constraint and isolate terms in $\mathrm{du} / \mathrm{d} \theta$ on the left to form

$$
\left(\frac{\Pi_{u}}{E_{u}}-\frac{\Gamma_{u}}{E_{u}} \frac{\Pi_{\tau}}{\Gamma_{\tau}}\right) E_{u} \frac{d u}{d \theta}=-\Pi_{\theta}-\Pi_{\tau} \frac{\Gamma_{\theta}}{\Gamma_{\tau}}=-\Pi_{\theta}\left(1-\frac{\Pi_{\tau}}{\Gamma_{\tau}} \frac{\Gamma_{\theta}}{\Pi_{\theta}}\right) .
$$


Here, the subscripts with respect to $\tau$ and $\theta$ denote derivatives with respect to scalar movements of corresponding vectors under government control. ${ }^{8}$

\section{The Marginal Cost of Funds Concept}

The structure of (1.8) suggests the concept of the Marginal Cost of

Funds (MCF). The MCF of a government instrument is defined as the ratio of the private budgetary impact of a change in the instrument to the government budgetary impact of a change in the instrument, holding other variables (notably the utility $u$ ) constant. The MCF of any instrument $i$ is:

$$
M C F^{i} \equiv \frac{\Pi_{i}}{\Gamma_{i}} .
$$

Trivially, $M C F^{\rho}=1$. For each instrument change, the MCF represents the compensation needed to support the initial utility per dollar of marginal net government revenue. Using the definition, equation (1.8) becomes:

$$
\left(\frac{\Pi_{u}}{E_{u}}-M C F^{\tau} \frac{\Gamma_{u}}{E_{u}}\right) E_{u} \frac{d u}{d \theta}=-\Pi_{\theta}\left(1-\frac{M C F^{\tau}}{M C F^{\theta}}\right)
$$

The usual analysis of the MCF is limited to a set of taxes while the structure of (2.1) extends readily to include the MCF of quotas, rent-retaining tariffs or indeed any other government instrument reform.

The interpretation of the MCF is sharpest in the effect on the government budget constraint of a loan or transfer from abroad, $d \beta$. Solving as in $\left(1.8^{\prime}\right)$ :

$$
\left(\frac{\Pi_{u}}{E_{u}}-M C F^{\tau} \frac{\Gamma_{u}}{E_{u}}\right) E_{u} \frac{d u}{d \beta}=M C F^{\tau}
$$

MCF here is the savings to the private (compensated) budget when a one dollar transfer finances the endogenous tax change $d \tau$. MCF $>1$ means that the tax is inefficient, reductions paid for by external loans more than pay for themselves.

\footnotetext{
${ }^{8}$ General forms of fiscal reform can be analyzed by replacing the uniform radial change with some rule $d \pi=D \pi d \tau$ where $\mathrm{D}$ is a diagonal matrix. The MCF of this reform is defined with reference to both $\tau$ and $D$.
} 
The MCF as defined here is a compensated concept. In contrast, much of the literature (see Snow and Warren, 1996) defines the MCF as an uncompensated concept. The Uncompensated MCF (UMCF) of instrument change $\tau$ is the money metric utility change with respect to $\beta$, using the endogenous instrument $\tau$ at the same time to balance the government budget. Solve equation (2.2) for $d u:^{9}$

$$
\begin{aligned}
U M C F^{\tau} & \equiv E_{u}\left(\frac{d u}{d \beta}\right)^{\tau}=\left(\frac{\Pi_{u}}{E_{u}}-\frac{\Gamma_{u}}{E_{u}} \frac{\Pi_{\tau}}{\Gamma_{\tau}}\right)^{-1} \frac{\Pi_{\tau}}{\Gamma_{\tau}} \\
& =\kappa^{\tau} M C F^{\tau} \text { where } \\
\kappa^{\tau} & =\left(\frac{\Pi_{u}}{E_{u}}-\frac{\Gamma_{u}}{E_{u}} M C F^{\tau}\right)^{-1} .
\end{aligned}
$$

The term $\kappa^{\tau}$ which differentiates UMCF from MCF is termed here the 'distortion multiplier'. It has appeared in the tariff and tax reform literature under various names, usually just making a brief appearance to check that it is positive. In the case where the endogenous tax is a lump sum tax, $M C F^{\rho}=1$ and distortion multiplier $\kappa^{\rho}$ is positive if all goods are normal (the 'Hatta normality condition'), since this guarantees $\Pi_{u} / E_{u}-\Gamma_{u} / E_{u}>0 .{ }^{10}$ With endogenous distortionary taxation, normality does not suffice since $M C F^{\tau}>1$ ordinarily and could be large enough to switch the sign of the multiplier.

${ }^{9}$ The literature often solves for MCF with primal methods, or sometimes assumes an indirect utility function in taxes without deriving it from first principles.

10 The elements of the distortion multiplier $\kappa^{\tau}$ are:

$$
\begin{aligned}
\frac{\Pi_{u}}{E_{u}} & =1-[1-(1-\omega)(1-\alpha)] q^{\prime} E_{q u} / E_{u}+G \bar{g}_{G_{u}} / E_{u} \\
& =1+[\omega+\alpha(1-\omega)] q^{\prime} p_{I}+G \tilde{g}_{G p} p_{I}
\end{aligned}
$$

and

$$
\begin{aligned}
\frac{\Gamma_{u}}{E_{u}} & =\left(\pi-\pi^{*}\right)^{\prime} E_{\pi u} / E_{u}-\alpha(1-\omega) q^{\prime} E_{q u} \\
& =\left(\pi-\pi^{*}\right)^{\prime} x_{I}+\alpha(1-\omega) q^{\prime} p_{I}+G \tilde{g}_{G p} p_{I} .
\end{aligned}
$$

Here, the subscript I denotes differentiation of the uncompensated demand and inverse demand with respect to the consumer's income. With MCF equal to one, the terms in G cancel. Then with normality the derivatives with respect to I form positive fractions which sum to less than one. 
Stability arguments can, however, still be used to defend the assumption that the distortion multiplier is positive (Hatta, 1977 and Fukushima, 1981). ${ }^{11}$

The difference between the compensated and uncompensated MCFs is consequential in the heterogeneous agent theory of this paper. The compensated MCF of a representative agent approximation of the economy can be interpreted as the sum of individual agents' compensating variations. In contrast, the uncompensated MCF is difficult to interpret directly when the underlying reality which is approximated contains many agents. ${ }^{12}$

In practice too there is a consequential difference between MCF and UMCF. First, and most important, MCF in its compensated form should be useful in sensitivity analysis of tax policies by comparing results across a variety of representations of a given economy and tax structure, or even across economies. In contrast, the uncompensated MCF cannot meaningfully be compared across structures. The practice of reporting uncompensated MCFs is problematic (Snow and Warren, 1996) for this reason. Not only will the distortion multipliers be inconsistent, unless the analysis reports the distortion multipliers it is not even possible to do a correct analysis. ${ }^{13}$ Second, the use of the uncompensated MCF concept invites confusion. The uncompensated MCF may often be compared to a marginal benefit which is

\footnotetext{
${ }^{11}$ The Fukushima proof can be extended to cover the endogenous distortionary taxation case of this paper.

${ }^{12}$ Nevertheless, the sufficient conditions of Section 6 imply that welfare rises if tax instrument $i$ is reduced and tax instrument $j$ is increased when the MCF of tax instrument $i$ exceeds the MCF of tax instrument $j$. The welfare effect of substituting one tax for another is signed by $1-M C F^{i} / M C F^{j}$, as will be shown below. The UMCF ratio is related to the MCF ratio by:
}

$$
\frac{U M C F^{i}}{U M C F^{j}}=\frac{M C F^{i}}{M C F^{j}} \frac{\Pi_{u} / E_{u}-M C F^{j} \Gamma_{u} / E_{u}}{\Pi_{u} / E_{u}-M C F^{i} \Gamma_{u} / E_{u}} .
$$

Equation (2.3) implies that (assuming both multipliers and both $\Pi_{u}$ and $\Gamma_{u}$ are positive)

$$
\begin{aligned}
& \frac{U M C F^{\prime}}{U M C F^{\prime}}>\frac{M C F^{\prime}}{M C F^{\prime}}>1 \text { or } \\
& \frac{U M C F^{\prime}}{U M C F^{\prime}}<\frac{M C F^{\prime}}{M C F^{\prime}}<1 .
\end{aligned}
$$

meaning that the UMCF ratio will ordinarily also correctly sign the efficiency of tax substitutions.

${ }^{13}$ See the Appendix to Anderson, 1996 for details on computation of the MCF. 
not multiplied by the distortion multiplier. (See Anderson and Martin, 1996, who point out many errors of this type in the literature.)

\section{The MCF of Quotas, Tariffs and Rent-retaining Tariffs}

The MCF as defined here is readily applicable to any tax or trade instrument. The MCF of rent-retaining tariffs is presented first, followed by reviewing the MCF of ordinary tariffs and ending with the MCF of quotas. With these MCFs and using the logic of equation (1.8'), Section 4 states gradual reform propositions.

\subsection{Rent-retaining Tariffs}

Applying the general definition of MCF to the rent-retaining tariff in the system (1.5)-(1.6), imposing a uniform radial change in the vector $d t^{q}=t^{q} d \tau^{q}$ (without loss of generality, since the composition of the vector is irrelevant):

$$
M C F^{\tau^{q}}=\frac{(1-\alpha)(1-\omega)}{1-\alpha(1-\omega)} \leq 1=M C F^{\rho} .
$$

The reason the rent-retaining tariff is 'cheaper' than the lump sum tax is that it extracts some rent at the margin from foreigners, with equivalenc only at $\omega$ equal to zero.

\subsection{Tariffs}

Uniform radial change in the tariff means $d \pi=\left(\pi-\pi^{*}\right) d \tau$, where $\tau$ is a scalar. Applying the definition of the MCF yields:

$$
\text { (3.2) } M C F^{\tau} \equiv \frac{E_{\pi}{ }^{\prime}\left(\pi-\pi^{*}\right)-[\omega+\alpha(1-\omega)] q^{\prime} E_{q \pi}\left(\pi-\pi^{*}\right)+G \bar{g}_{G \pi}\left(\pi-\pi^{*}\right)}{E_{\pi}{ }^{\prime}\left(\pi-\pi^{*}\right)+\left(\pi-\pi^{*}\right)^{\prime} E_{\pi \pi}\left(\pi-\pi^{*}\right)-\alpha(1-\omega) E_{q \pi}\left(\pi-\pi^{*}\right)+G \bar{g}_{G \pi}\left(\pi-\pi^{*}\right)} \text {. }
$$

To understand this complex expression it is helpful to temporarily remove both the quota and public good elements. Then the MCF of tariffs is equal to

$$
\frac{E_{\pi}^{\prime}\left(\pi-\pi^{*}\right)}{E_{\pi}^{\prime}\left(\pi-\pi^{*}\right)+\left(\pi-\pi^{*}\right)^{\prime} E_{\pi \pi}\left(\pi-\pi^{*}\right)}
$$

Then the MCF of tariffs is greater than one, it costs more than a dollar to raise a dollar of revenue with a distortionary tax, so long as the net revenue effect 
of a rise in tariffs is positive), or the denominator is positive (or tariff levels are on the upward sloping portion of the net revenue Laffer curve). In the general case

$$
\begin{aligned}
M C F^{\tau} & \equiv \frac{a-\omega q^{\prime} E_{q \pi}\left(\pi-\pi^{*}\right)}{a+\left(\pi-\pi^{*}\right)^{\prime} E_{\pi \pi}\left(\pi-\pi^{*}\right)} \text { where } \\
a & \equiv E_{\pi}^{\prime}\left(\pi-\pi^{*}\right)-\alpha(1-\omega) q^{\prime} E_{q \pi}\left(\pi-\pi^{*}\right)+G \bar{g}_{G \pi}\left(\pi-\pi^{*}\right) .
\end{aligned}
$$

If the net revenue effect of a rise in tariffs is positive, $a>0$. The presence of quotas affects the MCF according to how quotas substitute with the tariff ridden goods. If they are substitutes, $q^{\prime} E_{q \pi}\left(\pi-\pi^{*}\right)<0$. Then:

\section{Lemma 1}

The MCF of tariffs is greater than one if quotas and tariff ridden goods are substitutes and the net revenue effect of a rise in tariffs is positive.

The positive net revenue condition is more restrictive than in the absence of quotas or public goods, since it requires that a is positive and exceeds $-\left(\pi-\pi^{*}\right)^{\prime} E_{\pi \pi}\left(\pi-\pi^{*}\right)$. The first term of a is positive if net revenue $\mathrm{E}_{\pi}{ }^{\prime}\left(\pi-\pi^{*}\right)$ is positive. The second term of a is positive if quotas and tariff-ridden goods are substitutes, while the third term of a is negative if public goods and tariffridden goods are substitutes. The magnitude of the cross effect between public goods and tariffs, $G \bar{g}_{G \pi}\left(\pi-\pi^{*}\right)=-G r_{\pi}^{*}\left(\pi-\pi^{*}\right)$, is thus a significant empirical issue as it provides a route by which tax increases could decrease revenue.

\subsection{Quotas}

The MCF of quotas is based on a uniform radial change in the quota vector $\mathrm{q}: d q=q d \chi$ where $\chi$ is a scalar. Applying the definition of the MCF:

$$
M C F^{\alpha} \equiv \frac{(1-\omega)(1-\alpha)\left[-E_{q}-p^{*}-t^{q}\right]^{\prime} q-[1-(1-\omega)(1-\alpha)] q^{\prime} E_{q q} q+G \bar{g}_{G q} q}{\alpha(1-\omega)\left[-E_{q}-p^{*}-t^{q}\right]^{\prime} q+t^{q} q-\alpha(1-\omega) q^{\prime} E_{q q} q+\left(\pi-\pi^{*}\right)^{\prime} E_{\pi q} q+G \bar{g}_{G q} q} .
$$

The meaning of the MCF of quotas is best analyzed through the two polar cases of pure auction quotas and pure VERs. 
The MCF of pure auction quotas is based on all rent going to the government: $\omega=0, \alpha=1$ and $t^{q}=0$. Then, ignoring cross effects with $\pi$ and $\mathrm{G}, M C F^{x}$ reduces to

$$
\frac{-q^{\prime} E_{q q} q}{\left(p-p^{*}\right)^{\prime} q-q^{\prime} E_{q q} q} \text {. }
$$

The denominator is negative when $\mathrm{q}$ is such that revenue is decreasing in $\mathrm{q}$, which corresponds to the upward sloping portion of the revenue Laffer curve: tightening quotas will raise revenue. Then the MCF of quotas is positive and greater than one. This term is the counterpart to the no quotas or public goods case of the MCF of tariffs. With exact tariff equivalence, the MCF of quotas is equal to the MCF of the tariffs which are equivalent. ${ }^{14}$ Admitting the cross effects, the MCF of auction quotas is

$$
M C F^{x}=\frac{-q^{\prime} E_{q q} q+G \bar{g}_{G q} q}{\left(p-p^{*}\right)^{\prime} q-q^{\prime} E_{q q} q+\left(\pi-\pi^{*}\right)^{\prime} E_{\pi q} q+G \bar{g}_{G q} q} .
$$

With substitutability

$$
\begin{aligned}
\left(\pi-\pi^{*}\right)^{\prime} E_{\pi q} q & <0 \text { and } \\
G \bar{g}_{G q} q & >0 .
\end{aligned}
$$

Then we can state the quota equivalent of Lemma 1 :

\section{Lemma 2}

The MCF of auction quotas is greater than one if quotas and tariff ridden goods are weak enough substitutes (or complements) and the net revenue effect of a decrease in auction quotas is positive.

The condition that tightening the quota be revenue increasing is restrictive, as in Lemma 1.

The MCF of pure VERs is based on $\omega=1$ and $\alpha=0$, leading to

$$
M C F^{x}=\frac{-q^{\prime} E_{q q} q+G \bar{g}_{G q} q}{t^{q^{\prime}} q+\left(\pi-\pi^{*}\right)^{\prime} E_{\pi q} q+G \bar{g}_{G q} q}
$$

\footnotetext{
${ }^{14}$ This may be seen by defining the pair of MCF's as $-q^{\prime} E_{q q} d q /\left(-q^{\prime} E_{q q} d q+t^{\prime} d q\right)=q^{\prime} d p /\left(q^{\prime} d p+t^{\prime} d q\right)$ and $E_{\pi}{ }^{\prime} d \pi /\left(E_{\pi}{ }^{\prime} d \pi+t^{\prime} E_{\pi \pi} d \pi\right)=m^{\prime} d \pi /\left(m^{\prime} d \pi+t^{\prime} d m\right)$.
} 
In the absence of cross effects, the MCF of VERs is negative. The revenue effect of a rise in $q$ is positive while the compensation effect is negative. The presence of cross effects, with substitutability, may lower the revenue effect. The cross effect of quotas with public goods may make the compensation effect positive. However, it is quite plausible that the MCF of VERs is less than one, the denominator remaining positive and the numerator, if positive, being smaller.

$$
\begin{aligned}
& M C F^{x}=\frac{-p^{\prime} q / \varepsilon+G \bar{g}_{G q} q}{t^{q^{\prime}} q-\bar{\tau} p^{\prime} q+G \bar{g}_{G q} q}=\frac{-1 / \varepsilon+\eta}{\bar{\tau}^{q}-\bar{\tau}+\eta} \text { where } \\
& \eta=G \bar{g}_{G q} q / p^{\prime} q \\
& \bar{\tau}^{q}=t^{q} q / p^{\prime} q \\
& 1 / \varepsilon=q^{\prime} E_{q q} q / p^{\prime} q \\
& \bar{\tau}=\sum_{k=1}^{K} \sum_{i=1}^{M} \frac{\pi_{i}-\pi_{i}^{*}}{\pi_{i}} \frac{\pi_{i} E_{\pi_{i q} q} q_{k}}{\pi^{\prime} E_{\pi q} q} .
\end{aligned}
$$

Here, $\varepsilon$ is the aggregate elasticity of demand for the product group subject to quotas and $\bar{\tau}$ is a weighted average tariff (on the domestic base) of tariffs on the non-quota constrained imports. ${ }^{15}$ For sharp results, impose implicit separability (see Anderson and Neary, 1992) which means the weighted average tariff becomes the trade weighted average tariff and $\varepsilon$ is a parameter. For $\eta \varepsilon>1$ (which makes the numerator positive) the MCF of VERs is less than one so long as

$$
\bar{\tau}^{q}>\bar{\tau}-1 / \varepsilon \text {. }
$$

The average tariff on the domestic base is bounded below on $e^{16}$, so this condition is met even for rent-retaining tariffs equal to zero provided the aggregate elasticity is less than one. Even for infinite elasticity, the condition is plausible. In the US, the rent-retaining tariffs exceed the tariffs on unconstrained goods by a long margin (Anderson and Neary, 1994 and Anderson, 1991). Outside of the implicitly separable case, something like the same insight works: higher rent-retaining tariffs than other tariffs creates a

\footnotetext{
${ }^{15}$ Since not all weights are guaranteed to be positive, it is not a true average.

${ }^{16}$ Strictly, this requires positive weights to be guaranteed, as with the separable case.
} 
presumption that the MCF of VERs is less than one, as does a low elasticity of demand for quota-constrained goods. Collecting results:

\section{Lemma 3}

(i) The MCF of VERs is less than zero with weak cross effects.

(ii) The MCF of VERs is greater than zero and less than one with $\eta \varepsilon>1$ and $\bar{\tau}^{q}>\bar{\tau}-1 / \varepsilon$.

In the general case, the MCF of quotas depends on the rent share parameters and lies somewhere between the two pure cases, with all their qualifications about substitutability and revenue raising quotas.

\section{Reform Propositions}

The preceding results on MCFs can be put together with the method of analysis of Sections 1 and 2 to yield reform propositions.

\subsection{Tariffication}

Standard World Bank advice to developing nations is to convert quotas to tariffs first, then reduce the tariffs. Tariffication in practice means increasing the level of rent-retaining tariffs, as licenses are commonly given away. Tariffication appears to be a sound policy, since an exogenous increase in a rent-retaining tariff on a quota-constrained good matched by an endogenous cut in the tariffs on unconstrained goods appears to replace distortionary taxes with a lump sum tax at the margin. In fact, based on (3.1) the rent-retaining tariff is better than a lump sum tax in that it retains some of the rent otherwise captured by foreigners. Tariffication appears to be welfare increasing if the distortion multiplier for this case is positive, without further qualification. Since, however, the alternative endogenous tax may have MCF less than one as well, additional conditions are required.

Using the methods of Sections 1 and 2, the marginal efficiency is:

$$
\kappa^{\tau^{-1}} E_{u} \frac{d u}{d \tau^{q}}=-\left(1-\frac{M C F^{\tau}}{M C F^{\tau^{q}}}\right) \Pi_{\tau^{q}} t^{q}=-\left(1-\frac{M C F^{\tau}}{M C F^{\tau^{q}}}\right)(1-\omega)(1-\alpha) q^{\prime} t^{q}
$$


Under the stability condition, the distortion multiplier is positive. If the trade in question is not initially subsidized, $t^{q 1} q$ is non-negative. Then the change in welfare is signed by the large bracketed expression on the left. From (3.1) $M C F^{\tau^{q}}<1$. From (3.2) and the discussion which follows, $M C F^{\tau}>1$ under restrictions on substitutability. Thus:

\section{Proposition 1}

$A$ rise in rent-retaining tariffs offset with a revenue neutral fall in other tariffs is welfare improving if (a) quota-constrained goods are substitutes for tariff-ridden goods, (b) tariffs are set at less than the revenue maximizing level and (c) quotaconstrained trade is not initially subsidized.

Proposition 1 is interesting chiefly for its qualification. Beyond the standard non-subsidization condition, replacing a distortionary tax with a 'nondistortionary' tax at the margin can't be guaranteed to raise welfare without a substitutability restriction between tariff ridden goods on the one hand and public goods and quotas on the other hand. ${ }^{17}$ While plausible, this restriction may be violated when quota restrictions are found on final goods and tariffs are found on intermediate goods in a variety of production models, as emphasized by Lopez and Panagariya (1992). There is nothing paradoxical about the result that extra restrictions are needed. A marginal reduction in a distortionary tax from an initial positive level need not always be beneficial, so the extra conditions are needed to ensure that it is so.

\subsection{Quota Liberalization}

The general method of this paper yields the marginal efficiency of a quota liberalization $\mathrm{d} \chi$ offset by a tariff rise as

$$
\begin{aligned}
& \kappa^{\tau^{-1}} E_{u} \frac{d u}{d \chi}=-\Pi_{\chi}\left(1-\frac{M C F^{\tau}}{M C F^{\chi}}\right) \text { where } \\
& -\Pi_{\chi}=(1-\omega)(1-\alpha)\left[p-p^{*}-t^{q}\right]^{\prime} q-[1-(1-\omega)(1-\alpha)] p_{q} q+G \bar{g}_{G q}^{\prime} q .
\end{aligned}
$$

\footnotetext{
${ }^{17}$ More generally, the alternative tax is a consumption or income tax, but the same qualification must be entered to ensure that the MCF of the alternative tax is greater than one.
} 
The term $-\Pi_{x}$ multiplying the bracket term on the right hand side of (4.1) is always positive in its first two elements, but the third element is positive only if public goods and quotas are substitutes: $G \bar{g}_{G q}{ }^{\prime} q>0$. Assuming this is so, and given stability, welfare rises (falls) with a rise in quotas as $M C F^{\tau} / M C F^{\chi}<(>) 1$. Based on (3.2) and (3.3), the ranking is generally ambiguous in the auction quota case; both MCFs are above one. However, the interesting case of VERs (full rent loss to foreigners, or $\omega$ equal to one) yields the MCF of quotas to be plausibly less than one. Then the bracketed term must be negative if the MCF of quotas is positive and the MCF of tariffs is greater than one. Alternatively, the bracket term is positive if the MCF of quotas is negative.

\section{Proposition 2}

In the VER case with unsubsidized trade, a revenue neutral rise in quotas:

(i) is welfare-improving if cross effects between public goods and quotas and between tariff ridden goods and quotas are weak, and (ii) is welfare decreasing with sufficiently strong substitutability between public goods and quotas if the conditions of Lemma 1 and Lemma 3(ii) are met.

Proposition 2 stands in contrast to the ambiguity of results with auction quotas (which in the case of quotas only are equivalent to tariffs). There, the MCF exceeds one and the desirability of reform hangs on comparison with the MCF of the alternative tax. For VERs, the magnitude of the alternative MCF is irrelevant (so long as it is bounded above one). By extension, the larger is the share of rent lost to foreigners (or to rent-seeking) the more likely it is that the considerations of Proposition 2 control the welfare analysis.

A part of the significance of Proposition 2 is once again in the qualifications: even the 'obvious' case of a revenue neutral rise in pure VERs is not unambiguously welfare improving. In contrast to the tariff reform case, however, a plausible ex ante case can be made for quota reform. VERs (if not with all rent lost to foreigners) are common. Quota reform is less obviously appealing as it approaches the pure auction quota case. 


\section{When is Efficiency Enough?: The Many Household Case}

The representative agent method above focuses on efficiency only. The method is interpreted in the many household case as using the aggregate compensated $\mathrm{MCF}^{18}$ of the various taxes. The natural question is, when is this simplification harmless? In this section the social welfare analysis of tax reform in the many household case is decomposed into the efficiency factor of preceding sections, and a distributional factor. The distributional factor plays the role of the distortion multiplier in preceding sections, harmless so long as it is positive. The distributional factor is shown to be positive given sufficient conditions which restrict either the correlation of welfare weights and income effects across households or restrict the dispersion of welfare weights. The sufficient conditions may be plausible in many applications.

The distributional factor modifies the representative distortion multiplier with two elements, a composition effect and an equity effect. The composition effect corrects the average marginal propensity for aggregation bias arising from household-level real income changes interacting with differences in households' marginal propensities to spend on taxed goods. A non-negative composition effect is shown to be necessary for the existence of a consistent representative agent version of the economy even with equal welfare weights. The equity effect is due to the differences in household real income effects of tax changes interacting with differences in welfare weights. The analysis of the distributional factor is developed for the case of a reduction of one set of tariffs paid for with an increase of another set of tariffs. For simplicity, in this section there are no quotas ${ }^{19}$ and no domestic production of the public good --- it is purchased from abroad at constant price

\footnotetext{
${ }^{18}$ The aggregate MCF holds each agent's utility constant.

${ }^{19}$ The distribution of quota rent is highly unequal. However, the quota distribution problem differs in no essential way from the unequal distribution of factor payments problem which is analyzed in this section. Unequal changes in factor returns interacting with unequal household ownership of factors are much like unequal changes in quota premia interacting with unequal ownership of quota rights.
} 
$r^{*}$. The technology exhibits constant returns to scale, which may mean dummy factors are used to receive any residual returns.

The first subsection sets out the social welfare function and the basic many household model. The second subsection analyzes the social welfare consequence of the tax replacement experiment. The Appendix analyzes the case of a reduction of a set of tariffs paid for with a cut in public goods supply.

\subsection{The Many Household Setup}

The social welfare function is assumed to be individualistic, defined over the agents' utilities in some cardinal representation. For each agent this is the money metric of utility

$$
E^{i}\left(p^{0}, \pi^{0}, G^{0}, u^{i}\right)=e^{i}\left(p^{0}, \pi^{0}, G^{0}, u^{i}\right)-v^{i i} g_{v}\left(p^{0}, \pi^{0}, v\right)
$$

relative to some base price vector $\left(p^{0}, \pi^{0}\right)$ and government expenditure $G^{0}$. The social welfare function is defined as

$$
W\left(u^{1}, \ldots, u^{N}\right)=F\left(E^{1}\left(p^{0}, \pi^{0}, G^{0}, u^{1}\right), \ldots, E^{N}\left(p^{0}, \pi^{0}, G^{0}, u^{N}\right)\right) ; F_{i}>0, \forall i .
$$

For some policy change $d \theta$, social welfare changes by

$$
\frac{d W}{d \theta}=\sum_{i=1}^{N} F_{i} E_{u}^{i} \frac{d u^{i}}{d \theta}=\sum_{i=1}^{N} \xi_{i} \frac{d \mu^{i}}{d \theta} .
$$

The social welfare function applies ethical weights $F_{i}=\xi_{i}$ to changes in the money metric utility indicator, $d \mu^{i} / d \theta$ for a change in some parameter $\theta$, then sums the changes in weighted utilities. ${ }^{20}$

Tax change analysis in the many household case depends on a system of $\mathrm{N}+1$ constraints: the $\mathrm{N}$ household budget constraints and the government budget constraint. The individual household $j$ has a budget constraint

$$
E^{j}\left(p, \pi, G, u^{j}, v^{j}, v\right)-\rho^{j}=e^{j}\left(p, \pi, G, u^{j}\right)-v^{j \cdot} g_{v}(p, \pi, v)-\rho^{j}=0,
$$

\footnotetext{
${ }^{20} \mathrm{~A}$ simple form which should be useful in simulations is the constant relative inequality aversion function:

$$
W=\frac{1}{1-\alpha} \sum_{i=1}^{N}\left(E^{i}\right)^{1-\alpha}
$$

where $\alpha$ is the coefficient of relative aversion to inequality.
} 
where the $\mathrm{j}$ superscript denotes the $\mathrm{jth}$ household, and $g_{v}$ is equal to the vector of factor payments. Lump sum redistributions $\rho^{j}$ are incipiently permitted for clarity here. The private sector budget constraint system consists of (5.1) for $j=1, \ldots, N$. Due to constant returns to scale, the sum of household net expenditure is equal to the difference between aggregate expenditure and gross domestic product:

$$
\sum_{j=1}^{N} E^{j}\left(p, \pi, G, u^{j}, v^{j}, v\right)=\sum_{j=1}^{N} e^{j}\left(p, \pi, G, u^{j}\right)-g(p, \pi, v) .
$$

The government budget constraint is then equal to

$$
\left(p-p^{*}\right)^{\prime} \sum_{j=1}^{N} E_{p}^{j}(\cdot)+\left(\pi-\pi^{*}\right)^{\prime} \sum_{j=1}^{N} E_{\pi}^{j}(\cdot)-r^{*} G-\sum_{j=1}^{N} \rho^{j}=\beta,
$$

where (5.2) and Shephard's and Hotelling's Lemmas are used to derive the aggregate level of trade in the two groups of goods. The analysis will be based on changes in the system consisting of (5.1) for all agents and equation (5.3). It is important to note that while the adding up properties of the $E^{j}$ 's give rise to (5.3), the elements of

$$
E_{p}^{j}=e_{p}^{j}\left(p, \pi, G, u^{j}\right)-v^{j \cdot} g_{v p}(p, \pi, v)
$$

will generally have differing signs across households, due the magnification effect of commodity price changes upon factor prices and the uneven pattern of household ownership of factors of production. No restriction is placed upon these. ${ }^{21}$

It is convenient for the subsequent analysis to introduce some new notation. First, denote the aggregate trade vector $\sum E_{\pi}^{j}$ as $m$, and the aggregate trade vector $\sum E_{p}^{j}$ as $q$. Next, the vector of consumption of both groups of goods is denoted $x^{i}$ for household $\mathrm{i}$ and the entire tax vector (on

\footnotetext{
${ }^{21}$ The generality of the distributional model deserves emphasis. First, the model allows for complete generality in income distributional magnification effects such as the StolperSamuelson theorem, which guarantee that commodity price changes produce both winners and losers. Second, the welfare weights are in principle allowed to be general. Finally, the sufficiency conditions are over-sufficient, and the necessary and sufficient condition given below may well hold in a broad and operationally relevant class of economies. This question awaits empirical verification.
} 
both groups of goods) is denoted $t$. The effect of a rise in income of household $\mathrm{i}$ on tax revenue is

$$
\lambda^{i}=t^{\prime} x_{I}^{i}
$$

Denote $\lambda^{\prime}$ as the row vector of the $\lambda^{\prime}$. Household i's share of the national real income effect of an equiproportionate rise in $\pi$ is defined as

$$
\omega_{i}^{\tau}=\frac{\left(\pi-\pi^{*}\right)^{\prime} E_{\pi}^{i}}{\left(\pi-\pi^{*}\right)^{\prime} m}
$$

Similarly, the normalized effect of an equiproportionate rise in $\mathrm{p}$ on household $i$ is

$$
\omega_{i}^{\theta}=\frac{\left(p-p^{*}\right)^{\prime} E_{p}^{i}}{\left(p-p^{*}\right)^{\prime} q}
$$

Denote $\omega^{\kappa}$ as the column vector of the $\omega_{i}^{\kappa}$ for $\kappa=\tau, \theta$. With identical agents, the $\omega$ weights are tax shares (and equal to $1 / N$ ). With differing factor endowments, in contrast, not all the weights need be positive or less than one, though they must sum to one. Finally, denote $d \mu / d \beta$ as the column vector of the rates of change of money metric utility.

\subsection{Tariff Reform in the Many Household Case}

Consider tax reform in the shape of uniform radial replacement of one tax with another. The solution to individual utility changes is obtained in two steps. First, differentiate the government budget constraint (5.3) with respect to $\theta$, the exogenous scalar tax change variable, and solve for $d \tau / d \theta$, the endogenous scalar tax change variable. Second, substitute into the differential of the private budget constraints (5.1) and isolate the terms in the changes in utilities on the left hand side of the equation system. This results in:

$$
\begin{aligned}
& {\left[I-M C F^{\tau} \omega^{\tau} \lambda^{\prime}\right] \frac{d \mu}{d \theta}=-h^{\theta \tau} q^{\prime}\left(p-p^{*}\right) \quad \text { where }} \\
& h^{\theta \tau}=\omega^{\theta}-\frac{M C F^{\tau}}{M C F^{\theta}} \omega^{\tau} .
\end{aligned}
$$

The expression $h^{\theta \tau}$ is a general expression for the vector of household compensation 'shares' for fiscal substitution of any variable $\theta$ for any variable 
$\tau$. Isolating the vector of rates of change of money metric utilities on the left hand side of the equation system yields

$$
\frac{d \mu}{d \theta}=-\left[I-\omega^{\tau} \lambda^{\prime}\right]^{-1} h^{\theta \tau} q^{\prime}\left(p-p^{*}\right) .
$$

With convergence of the power series form of the inverse (guaranteed by stability) ${ }^{22}, \omega^{\tau_{1}} \lambda<1$ and the inverse may be rewritten to yield the vector of rates of change of money metric utilities as:

$$
\frac{d \mu}{d \tau}=-\left[I+\frac{\omega^{\tau^{\prime}} \lambda}{1-\omega^{\tau_{1}} \lambda} \omega^{\tau} \lambda^{\prime}\right] h^{\theta \tau} q^{\prime}\left(p-p^{*}\right)
$$

The social welfare effect of the tariff cut is a weighted sum of the above changes in money metric utility. The aggregation bias due to the composition effect is isolated by first imposing equal welfare weights. The Benthamite social welfare function change is obtained as:

$$
\frac{d W^{B}}{d \tau}=\frac{1}{N} l^{\prime} \frac{d \mu}{d \tau}=-\left[1-\frac{M C F^{\tau}}{M C F^{\theta}}\right]\left[1+\frac{M C F^{\tau} \omega^{\tau_{1}} \lambda}{1-M C F^{\tau} \omega^{\tau_{1}} \lambda} \bar{\lambda}\left(1+\frac{\operatorname{cov}\left(\lambda, h^{\theta \tau}\right)}{\bar{\lambda} \bar{h}^{\theta \tau}}\right)\right] q^{\prime}\left(p-p^{*}\right)
$$

Here, the bar over a variable such as $\mathrm{h}$ denotes the arithmetic mean of the vector $h$, and $\operatorname{cov}($.) denotes covariance. The product of the first and second terms reduces to the analysis of preceding sections, with MCF now explicitly an aggregate compensation measure. The third bracketed term of (5.6) is a distortion multiplier, guaranteed to be positive under the stability condition if in addition the covariance is non-negative, the composition effects condition. The composition effects factor $1+\operatorname{cov}\left(\lambda, h^{\tau p}\right) / \bar{\lambda} \bar{h}^{\tau p}$ in effect corrects the representative agent value of $\bar{\lambda}$ for aggregation bias. Note that if the factor is negative (perverse aggregation bias), no consistent aggregate representation of the economy exists for the analysis of the tax reform, because the implied "corrected" value of the representative $\bar{\lambda}$ is associated with unstable equilibrium. The normalized covariance can be rewritten as:

\footnotetext{
${ }^{22}$ Suppose that a transfer of $\mathrm{d} \beta$ begins a gradual adjustment to the equilibrium level of $\mathrm{d} \mu$ as in $d \mu_{t}=-M C F^{\tau} \omega^{\tau} d \beta+M C F^{\tau} \omega^{\tau} \lambda^{\prime} d \mu_{t-1}$. Stability of this process requires $M C F^{\tau} \lambda^{\prime} \omega^{\tau}<1$.
} 


$$
\frac{\operatorname{cov}\left(\xi, h^{\theta \tau}\right)}{\bar{\xi} \bar{h}^{\theta \tau}}=\sigma_{\xi h^{\theta \tau}} \frac{\sigma_{\xi}}{\bar{\xi}} \frac{\sigma_{h^{\theta \tau}}}{\bar{h}^{\theta \tau}} .
$$

The composition effects condition is met if either the correlation of $\lambda$ and the income changes is non-negative, or the dispersion of the $\lambda^{\prime} s$ is sufficiently small in relation to the dispersion of the income changes.

Finally, the main business of the analysis is the equity effect, arising with unequal welfare weights. Solving for the change in social welfare and using the algebra of covariance as in the preceding case,

$$
\frac{d W}{d \theta}=-\bar{\xi}\left[1-\frac{M C F^{\tau}}{M C F^{\theta}}\right]\left[1+\frac{\operatorname{cov}\left(\xi, h^{\theta \tau}\right)}{\bar{\xi} \bar{h}^{\theta \tau}}+\delta^{\tau} \bar{\lambda}\left(1+\frac{\operatorname{cov}\left(\xi, \omega^{\tau}\right)}{\bar{\xi} \bar{\omega}^{\tau}}\right)\left(1+\frac{\operatorname{cov}\left(\lambda, h^{\theta \tau}\right)}{\bar{\lambda}^{\theta \tau}}\right)\right] \mathrm{q}^{\prime}\left(\mathrm{p}-\mathrm{p}^{*}\right)
$$

where

$$
\delta^{\tau}=\frac{M C F^{\tau} \lambda^{\prime} \omega^{\tau}}{1-M C F^{\tau} \lambda^{\prime} \omega^{\tau}}
$$

The social desirability of the tax reform decomposes into the efficiency factor of preceding sections, dependent on the MCF of one tax versus that of another tax, and the distributional factor in the second large bracket term. If $\tau$ represents an endogenous change in a broad base tax, it is plausible that its equity effects are not perverse,

$$
1+\frac{\operatorname{cov}\left(\xi, \omega^{\tau}\right)}{\bar{\xi} \bar{\omega}^{\tau}}>0 \text {. }
$$

Then under the composition effects condition and the stability condition, the sign of the bracket term is positive if the equity effect of the tax substitution is not perverse,

$$
1+\frac{\operatorname{cov}\left(\xi, h^{\theta \tau}\right)}{\bar{\xi}^{\theta \tau}}>0
$$

There are two conditions under which the equity terms are positive, not perverse (using the alternative expression for normalized covariance).

Equity effects are not perverse if:

(a) household income changes and welfare weights are nonnegatively correlated, or 
(b) the product of the relative dispersion of the income changes and the relative dispersion of the welfare weights does not exceed one.

Then:

\section{Proposition 3 \\ Uniform radial replacement of tariffs with other taxes is welfare- improving if trade is not subsidized and (i) the MCF of tariffs exceeds the MCF of the replacement taxes, (ii) the stability condition holds, (iii) the composition effects condition holds and (iv) equity effects are not perverse.}

Perversity of the distribution effects of trade reform is most likely with a negative correlation of the household income effects $h^{\theta \tau}$ and the welfare weights in combination with sufficiently high dispersion of the welfare weights in comparison to the dispersion of the income effects.

In the face of very substantial ignorance about both income distributional linkages and ethical weights, and in the absence of evidence pointing to perverse distributional problems, it is reasonable to presume the sufficiency of the representative agent model and apply Proposition 3. Perverse cases are likely to be similar to the case of Mexico's accession to NAFTA (Levy and van Wijnbergen, 1995) where any reasonable model points to the losing group with high ethical weight. In such a case, as Levy and van Wijnbergen show, it is feasible to attack the distributional problem with a disaggregated model and additional distortionary government instruments to guarantee a Pareto-improvement so that losers will be compensated sufficiently. ${ }^{23}$

At the opposite pole is the full information approach where the welfare weights are assumed to be known. The optimal tax literature decomposes the optimal tax rate into an efficiency component and a distributional characteristic (Atkinson and Stiglitz, 1980, pp387-388). The

\footnotetext{
${ }^{23}$ Levy and van Wijnbergen's model has only a few aggregate agents, so the objection to the representative agent model applies also to their aggregates. The objection has force, since their assumed distributive instrument is irrigation and the model requires that millions of poor farmers on rain-drenched land (in the rebellious states of Chiapas and Quintana Roo) will be compensated with irrigation projects.
} 
distributional characteristics are normalized covariances similar to the covariance terms used above. An extension of this method to the gradual reform context is feasible mathematically, resulting in expressions which guarantee welfare improvement based on the MCFs, the distributional characteristics and the covariances of $\lambda$ with the real income changes. The defect is that the required information is not (credibly) available.

\subsection{Tariff Reform and Public Goods}

Distributional problems are especially likely if tariff reforms are paid for by cuts in public expenditures. For example, cuts in spending on public health and public education are likely to especially affect the poor. Thus it is important to extend the many household analysis to the case of spending cuts. $^{24}$

Public goods cuts in the many household case can again be decomposed into the aggregate efficiency factor and the distributional factor. The Appendix presents the details. The aggregate efficiency condition (replicating that in Anderson (1997) for the representative agent case) is that trade reform paid for by public goods cuts is welfare improving if the public goods are initially in excess supply in the intuitive sense that the marginal benefit is less than the full marginal fiscal cost of the goods, paid for at the margin by trade taxes. The distributional factor is again comprised of the composition effect and the equity effect.

The sufficient conditions for equity effects not to be perverse, as expected from the preceding analysis, are either that the correlation of the welfare weights and the household income effects is non-negative or that the relative dispersion of the welfare weights times the relative dispersion of the household income effects be smaller than one. There are two correlations to consider: that between the ethical weights and the household income effects of endogenous cuts in government spending, and that between the ethical

\footnotetext{
${ }^{24}$ I am grateful to Arja Turunen-Red for pointing this out to me, thus inspiring all ot Section 5.
} 
weights and the household income effects of the switch from tariffs to less government spending. As to the first, it may often be plausible that government spending cuts fall more heavily on the poor, who plausibly receive larger weights in most citizens' ethical valuations. Thus a negative correlation is often plausible. As to the second, the general equilibrium real income effects of the tariff cut must be considered along with the income effect of cuts in government spending. The only safe conclusion is that the representative agent approximation is especially problematic when trade liberalization is matched with government spending cuts.

\section{Conclusion}

Trade reform typically must face raising other taxes or cutting government spending in order to pay for the tariff revenue loss: an active budget constraint. The analysis of trade reform with an active government budget constraint, and by simple extension other tax reform, is placed on a firm footing in this paper. Government budget balance forces the endogenous use of distortionary tax instruments when an exogenous reform is implemented. The aggregate efficiency of such reforms is based on comparisons of simple summary measures of the Marginal Cost of Funds of the various tariff or quota changes, or of the Marginal Benefit of Government supplied goods. Unless equity considerations are perverse, social welfare rises with aggregate efficiency. Plausible conditions for non-perverse distributional effects are provided.

The theory of this paper forms a useful toolkit for practitioners. (1) The MCF of various tax packages is operational with simulation of CGE models, and the solution method is presented here. Since there is no general reason to expect the MCF of trade taxes to exceed the MCF of domestic taxation, it is by no means obvious that trade reform is beneficial. This suggests a research program in which MCFs of various taxes are calculated and with a variety of CGE models, to establish reasonable ranges of values. (2) The methods of Section 5 can be used to test whether the practice of ignoring equity 
considerations is plausible. The sufficient distribution conditions can be investigated for various tax reform packages and ethical weights within given CGE models, informing the 'guess' that dispersion and/or correlation is low. 


\section{References}

Ahmad, E. and N. Stern (1990), "Tax Reform and Shadow Prices in Pakistan" Oxford Economic Papers, 42, 135-159.

Anderson, J.E. (1997), "Trade Reform with a Government Budget Constraint", forthcoming in Trade Policy and the Pacific Rim, J. Piggott and A. Woodland, eds., Macmillan for the International Economic Association. (1996), "Trade Reform with a Government Budget Constraint", NBER

Working Paper 5827. and J.P. Neary (1994) "The Trade Restrictiveness of the Multi-Fibre Arrangement", with Peter Neary, World Bank Economic Review,, , 171-189. and J.P. Neary (1992), "Trade Reform with Quotas, Partial Rent Retention and Tariffs" Econometrica, 60, 57-76. (1991),"The Coefficient of Trade Utilization: the Cheese Case" in R.

Baldwin ed. Empirical Studies of Commercial Policy, NBER, Chicago: University of Chicago Press, 221-244.

Atkinson, A.B. and J.E. Stiglitz (1980), Lectures in Public Economics, New York: McGraw-Hill.

Bergsten, C. F., K. A. Elliott, J. Schott and W. E. Takacs, Auction Quotas and U.S. Trade Policy, Washington: Institute for International Economics.

Diamond, P. A. and J. Mirrlees (1971) 'Optimal taxation and public production', American Economic Review, 61,8-27 and 261-278.

Erzan, R., K. Krishna and L-H. Tan (1994), "Rent-sharing in the Multi-Fibre Arrangement: Theory and Evidence from U.S. Apparel Imports from Hong Kong", Review of International Economics, 2(1), 62-73.

Fukushima, T. (1981), "A Dynamic Quantity Adjustment Process in a Small Open Economy and the Welfare Effects of Tariff Changes", Lournal of International Economics, 11, 513-531.

Hatta, T. (1977), "A Theory of Piecemeal Policy Recommendations", Review of Economic Studies, 45, 1-21. 
Levy, S. and S. van Wijnbergen (1995), "Transition Problems in Economic

Reform: Agriculture in the North American Free Trade Agreement", American Economic Review, 85, 738-754.

Lopez, R. and A. Panagariya (1992) 'On the Theory of Piecemeal Tariff Reform: The Case of Pure Imported Intermediate Inputs', American Economic Review, 82, 615-625.

Snow, A. and R.S. Warren (1996), "The Marginal Cost of Funds: Theory and Evidence", Journal of Public Economics, 61, 289-305. 


\section{Appendix. Government Expenditure Cuts}

The new element in the analysis is to differentiate the government budget constraint and the system of private budget constraints by $G$, the supply of the public good. To simplify without loss of essentials, quotas are again assumed away. Public goods are now assumed to be produced domestically, as in the first sections (and in Anderson, 1997). Differentiation by $\mathrm{G}$ in the government budget constraint yields the marginal fiscal cost of public goods, defined as:

(8.1) $\gamma \equiv-\Gamma_{G}=-\bar{g}_{G}-G \bar{g}_{G G}-\left(\pi-\pi^{*}\right)^{\prime} m_{G}$.

Each term on the right hand side of (8.1) is likely to be positive. The first term is the marginal resource cost of a unit of $G$ and is always positive. The second term adds to this the marginal cost element due to the monopsony power of the government and is always positive in a convex economy. The third term is the tax revenue effect and will be positive as there is substitution away from taxed goods when the public goods supply increases, $m_{\pi G}<0$.

Differentiation by $\mathrm{G}$ in the private budget constraint for agent $i$ yields the private net marginal benefit of the public good ${ }^{25}$ :

$$
\tilde{r}^{i}=-\left[e_{G}^{i}-v^{i} \bar{g}_{v G}\right] \text {. }
$$

Summing across agents and using the constant returns to scale property of the gross domestic product function $\mathrm{g}\left(\pi, \mathrm{r}^{*}, \mathrm{v}\right)$ in $\mathrm{v}$, the Marginal Benefit of $\mathrm{G}$ is defined as: ${ }^{26}$

$$
M B G \equiv \sum_{i=1}^{N} r^{i}+v^{\prime} \bar{g}_{v G}=\sum_{i=1}^{N} r^{i}+G r_{G}^{*}
$$

The first term is the familiar sum of marginal valuations while the second term includes the net rise in private sector factoral income from the rise in government expenditure.

Now solve for the system of changes in household utilities when tariffs are cut exogenously with a uniform radial cut and the budget is balanced with a cut in G. Solving the change in the government budget constraint for the change in $G$ with respect to $\tau$ and putting together the new elements with the old, the solution to household utilities is obtained from:

$$
\begin{aligned}
{\left[I-\frac{M B G}{\gamma} \omega^{G} \lambda^{\prime}\right] \frac{d \mu}{d \tau} } & =-\omega^{\tau}+\frac{M B G}{\gamma M C F^{\tau}} \omega^{G}=\mathrm{h}^{\tau \sigma}, \text { where } \\
\omega^{G} & =\left\{\omega_{i}^{G}\right\}=\left\{\left(r^{i}+v^{i i} \bar{g}_{v G}\right) / M B G\right\} .
\end{aligned}
$$

Solving for the ethically weighted sum of household utilities using previous steps and assuming convergence of the matrix series:

\footnotetext{
${ }^{25}$ The public good is 'pure', so consumption is nonrival: all agents receive services in proportion to $\mathrm{G}$.

${ }^{26}$ The steps leading the result are: $v^{\prime} \bar{g}_{v}=g=\bar{g}-G \bar{g}_{G}$, and thus

$v^{\prime} \bar{g}_{v G}=\bar{g}_{G}-\bar{g}_{G}-G \bar{g}_{G G}=G r_{G}^{*}$. The restricted function $\bar{g}(\pi, G, v)$ is not homogeneous in ${ }^{\prime}$.
} 


$$
\begin{aligned}
\frac{d W}{d \tau} & =\xi^{\prime} \frac{d \mu}{d \tau} \\
& =\bar{\xi}\left[1-\frac{M B G}{\gamma M C F^{\tau}}\right]\left[1+\frac{\operatorname{cov}\left(\xi, h^{\natural G}\right)}{\bar{\xi} \bar{h}^{\tau G}}+k^{G} \bar{\lambda}\left(1+\frac{\operatorname{cov}\left(\xi, \omega^{G}\right)}{\bar{\xi} \bar{\omega}^{G}}\right)\left(1+\frac{\operatorname{cov}\left(\lambda, h^{\pi G}\right.}{\bar{\lambda}^{\tau G}}\right)\right] \text {, where } \\
k^{G} & =\frac{M B G\left(\omega^{G \cdot} \lambda\right) / \gamma}{1-M B G\left(\omega^{G \cdot} \lambda\right) / \gamma} .
\end{aligned}
$$

The first term gives the aggregate efficiency condition. It is positive if the MBG is less than the marginal fiscal cost of the public good times the MCF of the trade tax used to raise funds; i.e., if public goods are oversupplied. The second bracketed term is positive if the correlations of the ethical weights with the household income effects $h$ are non-negative, or if the dispersion of the ethical weights is sufficiently small, along with the stability condition and the composition effect condition on the distribution of marginal propensities to spend on taxed goods. 